Jurnal Sulolipu : Media Komunikasi Sivitas Akademika dan Masyarakat

Vol. 19 No.12019

e-issn : 2622-6960, p-issn : 0854-624X

\title{
EFEKTIFITAS ARANG TEMPURUNG KELAPA (Cocus nucifera L) DALAM MENURUNKAN KESADAHAN TOTAL PADA AIR \\ Rafidah $^{1}$ dan Elsafitri Muin Rayani ${ }^{2}$ \\ 1,2 Jurusan Kesehatan Lingkungan Poltekkes Kemenkes Makassar \\ yusufrafidah@gmail.com
}

\begin{abstract}
One of the chemical parameters in the water requirement is water hardness. Hardness is the term used in water containing the cation causing hardness. In general, hardness is caused by the presence of metals or cations of divalent 2, such as $\mathrm{Fe}, \mathrm{Sr}, \mathrm{Mn}$, $\mathrm{Ca}$ and $\mathrm{Mg}$. The purpose of this research is to know how the effectiveness of coconut shell charcoal in reducing total hardness in water. The type of research conducted is True Experiment with Pretest - Posttest Group Design design that is comparing the decrease of water hardness before and after being treated with coconut shell charcoal medium by using a combination of thickness variation and contact time. Based on this research it is known that there is a relationship between thickness variation and contact time with a decrease of total hardness in water. With the result that is at $10 \mathrm{~cm}$ thickness by using time variation 40,50, and 60 minutes obtained by sequence $7.82 \%, 11.25 \%$, and $12.5 \%$. As for the thickness of $20 \mathrm{~cm}$ with variations of time 40 minutes, 50 minutes, and 60 minutes obtained results $8.75 \%$ sequence, $13.76 \%$, and $19.16 \%$. While at $30 \mathrm{~cm}$ thickness with time 40 minutes, 50 minutes, 60 minutes sequentially obtained results $22.05 \%, 27.08 \%$, and $33.33 \%$. The conclusion of this research is the variation of thickness and contact time of charcoal and hard water able to decrease the hardness. So it can be an alternative in reducing hardness. For further researchers can use or combine other media so that the results of hardness filtration can occur decrease the hardness.
\end{abstract}

Keyword: Hardness, Coconut Shell Charcoal, Charcoal Thickness, Contact Time

\section{ABSTRAK}

Salah satu parameter kimia dalam persyaratan air bersih adalah kesadahan air. Kesadahan adalah istilah yang digunakan pada air yang mengandung kation penyebab kesadahan. Pada umumnya kesadahan disebabkan oleh adanya logam-logam atau kation - kation yang bervalensi 2, seperti $\mathrm{Fe}, \mathrm{Sr}, \mathrm{Mn}, \mathrm{Ca}$ dan $\mathrm{Mg}$. Tujuan penelitan ini adalah untuk mengetahui bagaimana efektifitas arang tempurung kelapa dalam menurunkan kesadahan total pada air. Jenis penelitian yang dilakukan adalah True Experiment dengan rancangan Pretest - Posttest Group Design yaitu membandingkan penurunan kesadahan air sebelum dan sesudah diberi perlakuan dengan media arang tempurung kelapa dengan menggunakan kombinasi variasi ketebalan dan waktu kontak. Berdasarkan penelitian ini diketahui bahwa terdapat hubungan antara variasi ketebalan dan kontak waktu dengan penurunan kesadahan total pada air. Dengan hasil yaitu pada ketebalan $10 \mathrm{~cm}$ dengan menggunakan variasi waktu 40,50, dan 60 menit diperoleh secara berurut $7.82 \%, 11.25 \%$ dan $12.5 \%$. Adapun pada ketebalan $20 \mathrm{~cm}$ dengan variasi waktu 40 menit, 50 menit, dan 60 menit diperoleh hasil secara berurut $8.75 \%, 13.76 \%$ dan $19.16 \%$. Sedangkan pada ketebalan $30 \mathrm{~cm}$ dengan waktu 40 menit, 50 menit, 60 menit secara berurut diperoleh hasil $22.05 \%, 27.08 \%$ dan 33.33\%. Kesimpulan dari penelitian ini adalah variasi ketebalan dan waktu kontak arang dan air sadah mampu menurunkan Kesadahan. Sehingga dapat menjadi salah satu alternatif dalam menurunkan kesadahan. Bagi peneliti selanjutnya dapat menggunakan atau menkombinasikan media yang lain sehingga hasil filtrasi kesadahan dapat terjadi penurunan kesadahan yang lebih baik.

Kata Kunci : Kesadahan, Arang Tempurung Kelapa, Ketebalan Arang, Waktu Kontak

\section{PENDAHULUAN}

Salah satu parameter kimia dalam persyaratan air bersih adalah kesadahan air. Kesadahan adalah istilah yang digunakan pada air yang mengandung kation penyebab kesadahan. Pada umumnya kesadahan disebabkan oleh adanya logam-logam atau kation - kation yang bervalensi 2, seperti $\mathrm{Fe}, \mathrm{Sr}$, $\mathrm{Mn}, \mathrm{Ca}$ dan $\mathrm{Mg}$.

Menurut Peraturan Menteri Kesehatan No.32 Tahun 2017 Tentang Standar Baku Mutu Kesehatan Lingkungan Dan Persyaratan Kesehatan Air Untuk Keperluan Higiene Sanitasi, Kolam Renang, Solus Per Aqua, Dan Pemandian Umum, batas maksimum kesadahan yang diperbolehkan adalah $500 \mathrm{mg} / \mathrm{l}$.

Menurut WHO, air yang bersifat sadah akan menimbulkan dampak terhadap kesehatan seperti penyumbatan darah jantung dan penyakit batu ginjal, di mana mengkonsumsi air dengan kadar kesadahan yang tinggi dapat menyebabkan penyakit gagal ginjal, serta menyebabkan pergerakan pada peralatan memasak serta pemborosan dalam pemakaian sabun karena buih yang dihasilkan sedikit.

Salah satu cara pengolahan yang sering dan umum dilakukan untuk mengatasi kesadahan adalah filtrasi (penyaringan). Filtrasi atau penyaringan merupakan proses untuk menurunkan kesadahan dalam air dan yang berperan dalam penyaringan ini adalah medianya. Media yang dapat digunakan yaitu dengan menggunakan arang aktif, pasir kuarsa dan zeolit.

\section{BAHAN DAN METODE}

\section{Lokasi Penelitian}

Penelitian pengolahan air dengan karbon aktif arang tempurung kelapa dilakukan di Kampus Kesehatan Lingkungan dan pemeriksaan kesadahan air 
dilakukan di Laboratorium Kimia Kesehatan Lingkungan.

\section{Desain Dan Variabel Penelitian}

Dilakukan pengolahan untuk menurunkan kesadahan pada air tersebut dengan menggunakan media arang tempurung kelapa dan pengolahan yang dilakukan yaitu secara kimia. Sebelum dilakukan pengolahan arang tempurung kelapa yang akan digunakan sebagai media dalam penurunan kesadahan ini telah diaktifkan terlebih dahulu dan kemudian dilakukan pemeriksaan dengan variasi lama kontak. Setelah pemeriksaan telah dilalukan dengan cara kimia kita akan mengetahui apakah dengan media arang tempurung kelapa dengan variasi ketebalan dan lama kontak efektif menurunkan kesadahan atau tidak.

Variabel Bebas adalah variabel yang akan diteliti variasi lama kontak arang tempurung kelapa sebagai adsorben selama 40 menit, 50 menit, 60 menit dengan ketebalan $10, \mathrm{~cm}, 20 \mathrm{~cm}$, dan 30 $\mathrm{cm}$. Variabel Terikat adalah variabel yang diduga terpengaruh oleh variabel bebas, dalam hal ini yang menjadi objek penelitian yaitu penurunan kesadahan total pada air. Variabel Pengganggu adalah variabel yang akan di ukur tetapi tidak diteliti yaitu $\mathrm{pH}$ dan suhu.

3. Populasi dan Sampel

Pada penelitian ini, air yang digunakan adalah air rekayasa, yaitu air bersih yang diberi tambahan kapur agar tingkat kesadahannya melebihi ambang batas. Adapaun kesadahan awal pada sampel yaitu : $81.705 \mathrm{mg} / \mathrm{l}$.

\section{Pengumpulan data}

Data Primer adalah data yang diperoleh dari pengamatan penelitian dan berdasarkan hasil pemeriksaan laboratorium yang telah dilakukan. Dengan data ini dapat diketahui efektifitas arang tempurung kelapa menurunkan kesadahan total. Data Sekunder adalah data yang diperoleh dari berbagai referensi baik jurnal, skripsi, buku, dan literatur serta penelusuran secara online yang dianggap dapat mendukung teori, serta memiliki keterkaitan dengan penelitian.

\section{Pengolahan dan Analisis Data}

Pengolahan dan analisa data yang digunakan adalah data yang telah diperoleh dari hasil pemeriksaan laboratorium dan dianalisa secara deskriptif komparatif digunakan untuk mencari persentasi penurunan kesadahan air. Kemudian menggunakan uji statistik parametris dengan uji analisis varian 2 arah (Two Way Anova). Untuk mengetahui apakah ada hubungan penurunan kesadahan total pada air dengan karbon aktif arang tempurung kelapa. Hasil dimasukkan dalam tabel, dan kemudian diuraikan dalam bentuk narasi dan dibuatkan kesimpulan.

\section{Hasil}

Penelitian ini merupakan penelitian eksperimen, dengan sampel air yang berasal dari air sumur yang telah direkayasa dengan penambahan bahan kapur. Sampel penelitian ini berjumlah 28 sampel, dimana 1 sampel awal, dan masing-masing 9 sampel pada penyaringan pertama, replikasi 1 dan replikasi 2. Dari penelitian yang telah dilakukan di peroleh hasil sebagai berikut.

\section{Hasil Penurunan Kesadahan Total Menggunakan Arang Tempurung Kelapa Dengan Variasi Ketebalan Dan Waktu}

\begin{tabular}{|c|c|c|c|c|c|c|c|}
\hline \multirow{2}{*}{$\begin{array}{c}\text { Keteba } \\
\text { lan }\end{array}$} & \multirow{2}{*}{$\begin{array}{c}\text { Awa } \\
I\end{array}$} & \multicolumn{6}{|c|}{ Waktu } \\
\hline & & $\begin{array}{c}40 \\
\text { menit }\end{array}$ & $\%$ & $\begin{array}{c}50 \\
\text { menit }\end{array}$ & $\%$ & $\begin{array}{c}60 \\
\text { menit }\end{array}$ & $\%$ \\
\hline Awal & $\begin{array}{l}87.8 \\
08 \\
\mathrm{mg} / \mathrm{l}\end{array}$ & & & & & & \\
\hline $10 \mathrm{~cm}$ & & $\begin{array}{l}80.9 \\
40 \\
\mathrm{mg} / \mathrm{l}\end{array}$ & $\begin{array}{l}7.82 \\
\%\end{array}$ & $\begin{array}{l}77.928 \\
\mathrm{mg} / \mathrm{l}\end{array}$ & $\begin{array}{l}11 . \\
25 \\
\%\end{array}$ & $\begin{array}{l}76.83 \\
1 \\
\mathrm{mg} / \mathrm{l}\end{array}$ & $\begin{array}{l}12 . \\
5 \%\end{array}$ \\
\hline $20 \mathrm{~cm}$ & & $\begin{array}{l}80.1 \\
24 \\
\mathrm{mg} / \mathrm{l}\end{array}$ & $\begin{array}{l}8.75 \\
\%\end{array}$ & $\begin{array}{l}75.730 \\
\mathrm{mg} / \mathrm{l}\end{array}$ & $\begin{array}{l}13 . \\
76 \\
\%\end{array}$ & $\begin{array}{l}70.97 \\
8 \\
\mathrm{mg} / \mathrm{l}\end{array}$ & $\begin{array}{l}19 . \\
16 \\
\%\end{array}$ \\
\hline $30 \mathrm{~cm}$ & & $\begin{array}{l}68.0 \\
51 \\
\mathrm{mg} / \mathrm{l}\end{array}$ & $\begin{array}{l}22.5 \\
\%\end{array}$ & $\begin{array}{l}64.026 \\
\mathrm{mg} / \mathrm{l}\end{array}$ & $\begin{array}{l}27 . \\
08 \\
\%\end{array}$ & $\begin{array}{l}58.53 \\
8 \\
\mathrm{mg} / \mathrm{l}\end{array}$ & $\begin{array}{l}33 . \\
33 \\
\%\end{array}$ \\
\hline
\end{tabular}

Dari tabel diatas maka, diketahui bahwa rata-rata penurunan tertinggi sebesar $33.33 \%$ atau $58.538 \mathrm{mg} / \mathrm{l}$ dengan ketebalan $30 \mathrm{~cm}$ dan waktu kontak 60 menit. Dan penurunan terendah yaitu sebesar $80.940 \mathrm{mg} / \mathrm{l}$ atau dengan perentase $7.82 \%$ dengan ketebalan $10 \mathrm{~cm}$ dan waktu kontak 40 menit.

Adapun grafik penurunan kadar kesadahan total pada air setalah melalui penyaringan dengan variasi ketebalan dan kontak waktu. 


\section{Grafik Penurunan Kesadahan Total Setelah Penyaringan Dengan Variasi Ketebalan Dan Kontak Waktu}

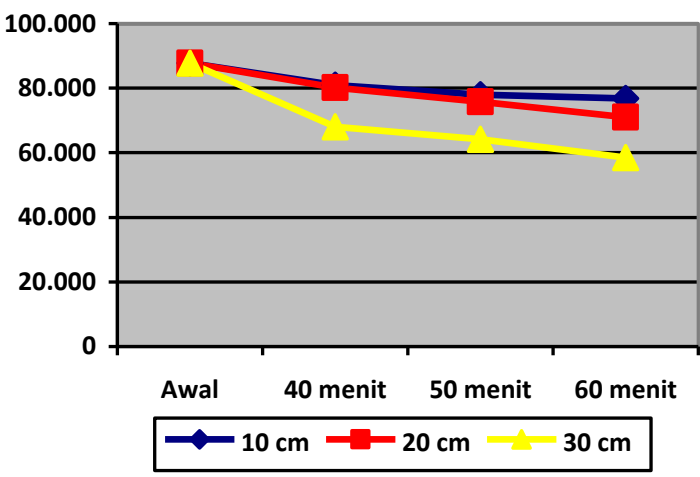

Dari grafik di atas dapat dilihat bahwa penurunan yang paling besar terjadi pada ketebalan $30 \mathrm{~cm}$ dengan kontak waktu 60 menit. Dan penurunan paling kecil atau sedikit terjadi pada ketebalan 10 $\mathrm{cm}$ dan waktu 40 menit.

Adapun untuk memperkuat hasil penurunan di atas maka dilakukan Uji statistik yaitu Uji Anova Dua Arah ( Two Way Anova). Adapun hasil uji statistik anova dua arah di peroleh hasil sebagai berikut :

Ketebalan arang dan waktu secara bersama-sama berpengaruh terhadap penurunan kesadahan dengan nilai sig. $0.000<$ 0.05 artinya terdapat pengaruh yang signifikan dalam penurunan kesadahan.

Variasi ketebalan arang terhadap penurunan kesadahan dengan nilai sig. $0.000<$ 0.05 artinya terdapat pengaruh yang signifikan terhadap penurunan kesadahan.

Waktu kontak terhadap penurunan kesadahan dengan nilai sig. $0.000<0.05$ artinya terdapat pengaruh yang signifikan terhadap penurunan kesadahan.

Interaksi Ketebalan* Waktu terhadap penurunan kesadahan dengan nilai sig. $0.418>$ 0.05 artinya tidak terdapat perbedaan yang signifikan terhadap penurunan kesadahan.

\section{Pembahasan}

Berdasarkan hasil penelitian kesadahan total dengan replikasi 3 kali yang dapat dilihat pada tabel 5.1 menunjukkan bahwa hasil pemeriksaan sampel awal untuk kadar kesadahan total adalah $87.808 \mathrm{mg} / \mathrm{l}$. Dan setalah dilakukan pengolahan dengan metode filtrasi dengan media arang tempurung kelapa dengan variasi ketebalan dan waktu menunjukkan penurunan paling besar adalah pada ketebalan $30 \mathrm{~cm}$ dan kontak waktu 60 menit. Dengan jumlah penurunan sebesar $58.538 \mathrm{mg} / \mathrm{l}$ atau dengan persentase $33,33 \%$. Dan penurunan paling rendah adalah $80.940 \mathrm{mg} / \mathrm{l}$ dengan persentase $7,82 \%$.
Pada ketebalan $10 \mathrm{~cm}$ dengan waktu kontak 40 menit terjadi penurunan kadar kesadahan dengan jumlah $80.940 \mathrm{mg} / \mathrm{l}$ dengan persentase $7,28 \%$. Sedangkan pada waktu 50 menit terjadi penurunan sebesar $77.928 \mathrm{mg} / \mathrm{l}$ dengan persentase $11,25 \%$. Dan pada 60 menit memiliki penurunan sebesar $12,5 \%$.

Adapun pada ketebalan $20 \mathrm{~cm}$ dengan waktu selama 40 menit diketahui terjadi penurunan sebesar $80.124 \mathrm{mg} / \mathrm{l}$ dengan persentase $8.75 \%$. Pada waktu 50 menit memiliki penurunan sebesar $75.730 \mathrm{mg} / \mathrm{l}$ dengan persentase $13.76 \%$. Dan waktu 60 menit terjadi penurunan sebesar $70.978 \mathrm{mg} / \mathrm{l}$ atau $19.16 \%$.

Pada ketebalan arang $30 \mathrm{~cm}$ dengan waktu selama 40 menit diperoleh hasil penurunan $68.051 \mathrm{mg} / \mathrm{l}$ atau $22.5 \%$ dan pada waktu 50 menit terjadi penurunan sebesar 64.026 dengan persentase $27.08 \%$. dan pada waktu selama 60 menit terjadi penurunan yaitu $58.538 \mathrm{mg} / \mathrm{l}$ atau dengan persentase $33.33 \%$.

Untuk memperjelas gambaran besar penurunan maka dapat dilihat pada grafik 5.1 yaitu grafik penurunan kesadahan total dengan variasi ketebalan dan waktu.

Dari hasil tersebut dapat diketahui bahwa variasi ketebalan arang tempurung kelapa dan kontak waktu dikatakan tidak efektif karena hanya mampu menurunkan sebanyak $33.33 \%$ yang paling tinggi. Jika menggunakan Skala Guttman, maka minimal besar penurunan kesadahan adalah $>50 \%$ hingga dapat dikatakan efektif. Pada sampel yang digunakan memiliki kadar awal yang besar yaitu $87.808 \mathrm{mg} / \mathrm{l}$. Sehingga penurunan $33.33 \%$ hanya mampu menurunkan hingga $58.538 \mathrm{mg} / \mathrm{l}$. Tidak sesuai pula dengan Permenkes 32 Tahun 2017 dengan standar kesadahan $500 \mathrm{mg} / \mathrm{l}$ karena sampel awal yang terlalu tinggi.

Dari penelitian ini pula dapat dilihat bahwa dengan variasi ketebalan dan waktu yang berbeda memberikan hasil penurunan yang berbeda pula. Semakin tebal dan lama waktu kontak air dan arang tempurung kelapa maka semakin besar pula tingkat penurunan kesadahan total. Hal ini dikarenakan semakin tebal media dan semakin lama waktu kontak air dan arang maka semakin besar pula kemampuan media dalam menurunkan kesadahan.

Arang aktif adalah arang yang diproses sedemikian rupa sehingga pori-porinya terbuka, dengan demikian arang aktif mempunyai daya serap yang dapat menghilangkan partikel-pertikel dalam air dan menurunkan tingkat kesadahan. Arang aktif sangat efektif dalam menyerap zat terlarut dalam air baik organik maupun anorganik karena mempunyai luas permukaan yang sangat luas.(Nana Ristiana,2009) 
Jurnal Sulolipu : Media Komunikasi Sivitas Akademika dan Masyarakat

Vol. 19 No.12019

e-issn : 2622-6960, p-issn : 0854-624X

Komponen penyusun kimiawi tempurung kelapa berdasarkan penelitian yang telah dilakukan adalah seperti berikut: $74,3 \%$ karbon, 21,09\% Oksigen, 0,2\% Silika, 1,4\% Kalium, 0,5\% Sulfur, 1,7\% Pospor menjadikanya bepeluang sebagai sumber bahan bakar dan sumber karbon aktif. (Esmar budi,2011)

Selain itu perlu dipahami mengenai sifat fisik dan kimia dari tempurung kelapa seperti bahan campuran (moisture), kerapatan, struktur morfologi dan termal. Perubahan tempurung kelapa menjadi arang dilakukan memalui proses pirolisis (pemanasan). Pada proses pirolisis unsur-unsur bukan karbon seperti hidrogen dan oksigen akan hilang hingga menyisakan sebanyak mungkin karbon dalam bahan.

Sifat fisik karbon aktif yang dihasilkan tergantung pada kekuatan daya tarik molekul penjerap maka terjadi proses absorpsi dari bahan yang digunakan, misalnya, tempurung kelapa menghasilkan arang yang lunak dan cocok untuk menjernihkan air, yaitu proses penyerapan zat - zat yang akan dihilangkan oleh permukaan arang aktif, termasuk $\mathrm{CaCO}_{3}$ yang menyebabkan kesadahan. Kemampuan karbon aktif menyerap secara kimia adalah tersuspensinya kedalam air sampel sehingga karbon aktif yang tersuspensi berpengaruh terhadap pengikat ion $\mathrm{Mg}$ dan $\mathrm{Ca}$. Proses reaksi kimianya sebagai berikut:

$$
\mathrm{C}^{4+}+3 \mathrm{H}_{2} \mathrm{O} \rightarrow 2 \mathrm{CO}_{3}+\mathrm{H}_{2}
$$

Proses pertukaran ion $\mathrm{Ca}^{2+}$ dan $\mathrm{Mg}^{2+}$ sangat cepat antara ( 20 - 30 menit ), dengan terbentuknya endapan $\mathrm{CaCO}_{3}$ atau $\mathrm{MgCO}_{3}$ berarti air tersebut telah bebas dari ion $\mathrm{Ca}^{2+}$ dan $\mathrm{Mg}^{2+}$ atau dengan kata lain air tersebut telah terbebas dari kesadahan.

Hasil penelitian ini bertolak belakang dengan hasil penelitian yang pernah dilakukan oleh Emmi Bujawati,dkk (2013). Dimana pada penelitian sebelumnya menggunakan media arang tempurung kelapa dengan variasi ketebalan $60 \mathrm{~cm}, 70 \mathrm{~cm}$, dan $80 \mathrm{~cm}$. Dengan hasil masing-masing $72,71 \%, 16.03 \%$ dan $20,05 \%$. Hasil ini tidak sesuai dengan teori yang menyatakan bahwa semakin tebal arang dan lama kontak waktu maka diperoleh hasil yang lebih baik.

Hasil penelitian ini sejalan dengan penelitian yang telah dilakukan oleh Ilhami arni(2013), pengaruh lama kontak karbon aktif terhadap penurunan kesadahan air sumur di Desa Kismoyoso, Kecamatan Ngemplak, Kabupaten Boyolali, yaitu bahwa semakin lama kontak waktu dan semakin tebal arang maka terjadi penurunan yang besar pula. Dengan menggunakan variasi waktu 10 menit, 20 menit dan 30 menit diperoleh hasil 23.25\%, 35.85\% dan $54.37 \%$. Maka hasil penelitian ini sejalan.
Penelitian lainnya yaitu keefektifan ketebalan kombinasi zeolit dengan arang aktif dalam menurunkan kadar kesadahan air sumur di Karang Tengah Weru Kabupaten Sukoharjo oleh Nana ristiana, dkk(2009). Hasil penelitian ini yaitu pada ketebalan $60 \mathrm{~cm}$ sebesar $71.54 \%$, pada ketebalan media $70 \mathrm{~cm}$ diperoleh hasil $94.36 \%$ dan pada ketebalan $80 \mathrm{~cm}$ dengan hasil $92,3 \%$.

Dalam melakukan penelitian ini, sampel air yang digunakan merupakan air sumur gali yang selanjutnya ditambahkan kapur sehingga memiliki kadar kesadahan atau biasa disebut dengan sampel rekayasa. Adapun metode penyaringan yang digunakan adalah metode up flow. Up Flow adalah proses filtrasi dari bawah ke atas pada media filtasi. Dengan sistem penyaringan dari arah bawah ke atas memiliki kelebihan jika saringan telah jenuh atau buntu, dapat dilakukan pencucian balik dnegan cara membuka kran penguras. Dengan adanya pengurasan ini, air bersih yang berada di atas lapisan teratas dapat berfungsi sebagai air pencuci media penyaringan (back wash). Dengan demikian pencucian media penyaring pada saringan pasir lambat Up Flow tersebut dilakukan tanpa mengeluarkan atau mengeruk media filter.

Penelitian ini dilakukan selama satu minggu dimana untuk membakar arang tempurung kelapa dilakukan selama 2 hari berturut, proses perakitan alat 1 hari dan filtrasi selama 1 dan pemeriksaan kesadahan selama 1 hari.

Adapun uji statistik yang digunakan adalah uji anova dua arah (Two Way Anova). Uji anova dua arah atau anova dua jalur digunakan untuk menguji hipotesis perbandingan lebih dari dua sampel dan setiap sampel terdiri atas 2 jenis atau lebih secara bersama-sama.

Berdasarkan hasil uji statistik yaitu Two Way Anova, diperoleh hasil yang tertera pada tabel 5.2 menunjukkan hasil bahwa pengaruh ketebalan dan waktu secara bersama-sama terhadap penurunan kesadahan dengan nilai sig. $0.000<0.05$ artinya terdapat pengaruh yang signifikan. Sedangkan pengaruh ketebalan terhadap penurunan kesadahan dengan nilai sig. $0.000<0.05$ artinya terdapat pengaruh yang signifikan. Dan pengaruh waktu terhadap penurunan kesadahan dengan nilai sig. $0.000<$ 0.05 artinya terdapat pengaruh yang signifikan. Serta interaksi ketebalan* waktu terhadap penurunan kesadahan dengan nilai sig. $0.418>$ 0.05 artinya tidak terdapat perbedaan yang signifikan.

Maka dapat diketahui bahwa faktor ketebalan dan waktu memiliki nilai signifikan 0.000 < dari 0.05 artinya hipotesis $\mathrm{H}_{0}$ ditolak dan 
Jurnal Sulolipu : Media Komunikasi Sivitas Akademika dan Masyarakat

Vol. 19 No.12019

e-issn : 2622-6960, p-issn : 0854-624X

Ha diterima yaitu terdapat pengaruh yang signifikan yang terjadi antara variasi ketebalan arang dan waktu kontak terhadap penurunan kesadahan total pada air. Meskipun memiliki pengaruh yang signifikan tetapi interaksi antara ketebalan dan waktu tersebut tidak memberikan perbedaan penurunan hasil yang signifikan, Artinya perbedaan penurunan tidak jauh berbeda setiap varisi ketebalan arang dan waktu kontak.

\section{Kesimpulan dan Saran}

\section{Kesimpulan}

Dari penelitian ini dapat disimpulkan bahwa perbedaan ketebalan media dan waktu kontak yang digunakan tidak efektif menurunkan kesadahan total pada air dengan rincian sebagai berikut :

a. Penurunan kesadahan total pada air dengan ketebalan arang $10 \mathrm{~cm}$ dengan waktu kontak 40 menit adalah sebesar $7.82 \%$, sedangkan waktu kontak 50 menit sebesar $11.25 \%$ dan pada waktu kontak 60 menit sebesar $12.5 \%$

b. Penurunan kesadahan total pada air dengan ketebalan arang $20 \mathrm{~cm}$ dengan waktu kontak 40 menit adalah sebesar $8.75 \%$, sedangkan waktu kontak 50 menit sebesar $13.76 \%$ dan pada waktu kontak 60 menit $19.16 \%$

c. Penurunan kesadahan total pada air dengan ketebalan arang $30 \mathrm{~cm}$ dengan waktu kontak 40 menit adalah sebesar $22.5 \%$, sedangkan waktu kontak 50 menit sebesar $27.08 \%$ dan pada waktu kontak 60 menit $33.33 \%$

\section{Saran}

a. Bagi Masyarakat

Penggunaan media arang tempurung kelapa hendaknya dipakai sebagai salah satu alternatif dalam menurunkan kesadahan pada air bersih karena bahan mudah ditemukan dan murah.

b. Bagi Peneliti Selanjutnya

Bagi peneliti selanjutnya dapat diteruskan dengan menggunakan atau menkombinasikan media yang lain sehingga hasil filtrasi kesadahan dapat terjadi penurunan kesadahan yang lebih besar dan lebih efektif.

\section{DAFTAR PUSTAKA}

Alfiana Sintari. 2015. Kemampuan Batu Coral Dalam Menurunkan Kesadahan ( $\left.\mathrm{CaCO}_{3}\right)$. Makassar. Politeknik Kesehatan Makassar.(KTI Tidak dipublikasikan).

Aliya D.R. Mengenal Teknik Penjernihan Air. Semarang : Penerbit Aneka IImu.

Chasan S, Kusnadi. 2002. Statistik Kesehatan. Makassar : Politeknik Kesehatan Makassar.

Emmy Bujawati, et al. 2013. Pengaruh Ketebalan Arang Tempurung Kelapa Terhadap Tingkat Kesadahan Air Di Wilayah Kerja Puskesmas Sudu Kabupaten Enrekang. Jurnal Kesehatan Vol.1

(Online).http://download.portalgaruda.org/article.php?article=445829\&val=6399\&title=PENG ARUH\%20KETEBALAN\%20ARANG\%20TEMPURUNG\%20KELAPA\%20TERHADAP\%20T INGKAT\%20KESADAHAN\%20AIR\%20DI\%20WILAYAH\%20KERJA\%20PUSKESMAS\%20 SUDU\%20KABUPATEN\%20ENREKANG\%20TAHUN\%202013 Diakses pada 11 Desember 2017

Esmar Budi, et al. 2013. Sifat Thermal Karbon Aktif Berbahan Arang Tempurung Kelapa. Jurnal Seminar Nasional Fisika Vol.2 : 73-81

Gilar S.2013. Pembuatan Karbon Aktif Dari Arang Tempurung Kelapa Dengan Aktivator $\mathrm{Zncl}_{2}$ Dan $\mathrm{Na}_{2} \mathrm{CO}_{3}$ Sebagai Adsorben Untuk Mengurangi Kadar Fenol Dalam Air Limbah.(Online). https://media.neliti.com/media/publications/149022-ID-pembuatan-karbon-aktif-dari-arangtempur.pdf Diakses pada 11 Desember 201

Hefni Effendi. 2003. Telaah Kualitas Air Bagi Pengelolaan Sumber Daya dan Lingkungan Perairan. Yogyakarta : Kanisius.

Ilhami Arni Lustiningrum. 2013. Pengaruh Lama Kontak Karbon Aktif Terhadap Penurunan Kadar Kesadahan Air Sumur Di Desa Kismoyoso Kecamatan Ngamplak Kabupaten Boyolali. (Online). http://eprints.ums.ac.id/27239/16/02._JURNAL_PUBLIKASI.pdf Diakses pada 20 Desember 2017. 
Jurnal Sulolipu : Media Komunikasi Sivitas Akademika dan Masyarakat

Vol. 19 No.12019

e-issn : 2622-6960, p-issn : 0854-624X

Kusnaedi. 2010. Mengolah Air Kotor Untuk Air Minum. Jakarta : Penebar Swadaya.

Mifbakhuddin.2010. Pengaruh Ketebalan Karbon Aktif Sebagai Media Filter Terhadap Penurunan Kesadahan Air Sumur Arteti. Jurnal Eksplanasi Vol.5 (2). Online). www.kopertis6.or.id Diakses pada 9 Januari 2018.

Mirham Mauluddin.2015.Studi Kualitas Air Sumur Daerah Sekitar Muara Sungai Tallo Dan Potensi Pemanfaatnya Sebagi Sumber Air Masyarakat (Skripsi). Makassar :Universitas Hasanuddin

Nana Ristiana, et al. 2009. Keefektifan Ketebalan Kombinasi Zeolit Dengan Arang Aktif Dalam Menurunkan Kadar Kesadahan Air Sumur Di Karangtengah Weru Kabupaten Sukoharjo.(Online). www.ums.ac.id Diakses pada 20 Desember 2017.

Republik Indonesia.2017. Permenkes Nomor 32 Tahun 2017 Tentang Standar Baku Mutu Kesehatan Lingkungan dan Persyaratan Kesehatan Air Untuk Keperluan Higiene Sanitasi, Kolam Renang, Solus Per Aqua, dan pemandian Umum.

Riduwan. 2015. Dasar-Dasar Statistik. Bandung : Alfabeta

Srikandi Fardiaz. 1992. Polusi Air dan Udara. Yogyakarta: Kanisius

Sugiharto. 1983. Penyediaan Air Bersih Bagi Masyarakat. Jakarta : Sekolah Pembantu Penilik Kesehatan.

Suhartana.2006.Pemanfaatan Tempurung Kelapa Sebagai Bahan Baku Arang Aktif Dan Aplikasinya Untuk Penjernihan Air Sumur Di Desa Belor Kecamatan Ngaringan Kabupaten Grobogan. Jurnal Berkala Fisika Vol 9 (3) : 154 - 161

Sujana Alamsyah.2007.Merakit Sendiri Alat Penjernih Air Untuk Rumah Tangga.Jakarta Selatan:Kawan Pustaka.

Sumadi Suryabrata. 2011. Metodolgi Penelitian.Jakarta : PT.Raja Grafindo Persada. 